\title{
Escenarios sonoros del poder municipal en España durante la Edad Moderna: el caso de Jerez de la Frontera
}

\section{Sound scenarios of municipal power in Spain during the Modern Age: the case of Jerez de la Frontera}

\author{
Juan Antonio Moreno Arana \\ Investigador independiente \\ jarenoara@gmail.com \\ https://orcid.org/0000-0002-9861-7740
}

Fecha de recepción: 6/10/2020

Fecha de aceptación: 14/01/2021

\section{RESUMEN}

En el marco temporal que transita entre fines de la Edad Media y a lo largo de la Edad Moderna fructifica la progresiva integración de la música dentro de las prácticas sociales, ceremoniales y festivas que ponen en escena la imagen de las oligarquías urbanas. Este trabajo estudia la evolución de este fenómeno a partir de las completas fuentes documentales del Archivo Municipal de Jerez de la Frontera.

Palabras clave: Música, Músicos, Oligarquías, Solemnidades públicas.

Topónimos: Jerez de la Frontera.

Período: Edad Moderna.

\section{ABSTRACT}

In the time frame running between 1500 and 1800, there was increased integration of music into different social practices and various ceremonial and festive scenarios in which the image of the local oligarchies was staged. This work studies the evolution of this phenomenon on the basis of the complete documentary sources of the Municipal Archives of Jerez de la Frontera

Key words: Music, Musicians, Oligarchies, Public solemnities.

Toponyms: Jerez de la Frontera.

Period: Modern Age. 


\section{INTRODUCCIÓN.}

El trasvase de los códigos musicales del ceremonial áulico y eclesiástico al resto de instituciones, fenómeno que experimenta su máximo alcance durante los siglos modernos $^{1}$, tiene en Jerez de la Frontera un caso particularmente interesante de estudio ${ }^{2}$; su privilegiada situación geoestratégica, unida a su dilatado y copioso alfoz, la integran en las redes comerciales de los emporios de Sevilla y Cádiz, elevando el tono social y cultural de la ciudad jerezana con respecto a otros núcleos de la región ${ }^{3}$. En este contexto de incesante fluir de dinero, personas e ideas tiene lugar una temprana adopción de lo sonoro como engranaje de la Potestas y de la Auctoritas de la institución concejil jerezana. Unas prácticas musicales en las que habría que valorar el efecto de la presencia extranjera, y en especial la italiana, que se injerta en la oligarquía local desde fines de la Edad Media y de la permanente cercanía espacial y de trato político y personal con la corte real de Enrique IV o con casas nobiliarias como las de los Ribera o los Medina Sidonia como agentes impulsores de la identidad nobiliaria a través de la música ${ }^{4}$.

Partiendo de estas coordenadas, las páginas que siguen pretenden, desde la base las completas fuentes documentales del archivo capitular de Jerez, en coordinación con fuentes narrativas de ciertos eventos ceremoniales o festivos, determinar, en primer lugar, la naturaleza de la elección de distintas tipologías de músicos e instrumentos para el servicio de este grupo dirigente jerezano a lo largo de la Edad Moderna. En un segundo punto, el objetivo ha sido delimitar, desde este contexto, la sonorización de los distintos escenarios del ceremonial urbano que protagoniza el gobierno municipal.

\section{MÚSICOS AL SERVICIO DE LA INSTITUCIÓN MUNICIPAL JEREZANA. SIGLOS} XV-XVIII.

\subsection{Músicos municipales.}

Repasaremos aquellos instrumentistas que formalizan un contrato y cuentan con un salario estable con la institución municipal, considerándolos, por consiguiente, como empleados municipales ${ }^{5}$.

De forma genérica, son los conjuntos instrumentales de viento los que, junto con la percusión, se eligen por su alta sonoridad para afirmar la imagen del poder civil local en los distintos espacios urbanos al aire libre ${ }^{6}$.

\subsubsection{Trompetas y ministriles.}

Las primeras noticias documentales sobre músicos con una vinculación estable con el Ayuntamiento de Jerez de la Frontera se sitúan a principios del siglo XV; en 1414 ya

1 Los estudios que han prestado atención monográfica al papel de la música en la escenificación del poder urbano en España han tenido un amplio recorrido historiográfico en las dos últimas décadas. En la bibliografía final hacemos una selección de algunos de los estudios más representativos.

2 Un primer acercamiento en: J. A. Moreno Arana, "Música y poder municipal en Jerez de la Frontera. Siglos XVI-XVII", Historia, Instituciones y Documentos, 45, (2018), pp. 241-268.

3 H. Sancho de Sopranis y J. Lastra Terry, Historia de Jerez de la Frontera, tomo II, Jerez, 1965, pp. 51-69.

4 Con respecto a la música en la formación ética e intelectual nobiliaria en la Italia del Renacimiento véase, por ejemplo: S. Lorenzetti, Musica e identità nobiliare nell'italia del Rinascimento Educazione, Mentalità, Immaginario, Florencia, 2003. Sobre las "cortes musicales" españolas en el siglo XV: C. Bejarano Pellicer, "De las alegrías medievales a las solemnidades barrocas: las raíces del paisaje sonoro festivo de la España moderna en la crónica del condestable Miguel Lucas de Iranzo", en Paisajes sensoriales, sonidos y silencios de la Edad Media. Mar del Plata, Universidad Nacional de Mar del Plata, 2016, p. 247.

5 El reclutamiento de músicos municipales en: C. Bejarano Pellicer, El mercado de la música en la Sevilla del Siglo de Oro, Sevilla, Universidad de Sevilla, 2013, pp. 232-300; J. A. Moreno Arana, "Música...", pp. 254-264.

6 C. Bejarano Pellicer, El mercado..., p. 224. 
consta la presencia de un "trompeta del Concejo"7. Aunque se ha argumentado lo contrario para otros $\operatorname{casos}^{8}$, en la Jerez medieval los contratos que el ayuntamiento realiza con estos instrumentistas expresan un alto grado de profesionalización y el carácter de funcionario municipal. En 1437, el portugués Alvar Gómez entra al servicio del cabildo por ser "buen trompeta", con un salario anual de dos mil maravedíes, con la añadidura de doscientos maravedíes para "el alquiler de la casa en que more"9. En 1484, se propone la contratación de un trompeta, "que es buen mucico [...] y usa bien del oficio". Con ello, el cabildo afirmaba que dispondría de "dos trompetas", de manera que "saliese la cibdad lo más honrrada que ser pueda". Se acordó traerlo a la ciudad y ofrecerle un sueldo anual de cuatro mil maravedíes ${ }^{10}$.

Jerez de la Frontera hay que sumarla, pues, a ese grupo de ciudades que por toda la Europa del Trescientos y el Cuatrocientos sustentan su Honra en todas sus salidas públicas en el sonido de las trompetas, ya fuera por actos civiles, como por rebatos militares.

La asimilación entre "trompeta" y "músico" que hacen los regidores jerezanos permite reconsiderar el papel dado a estos trompetistas concejiles como meros ejecutores no profesionalizados de una estricta función de proyección sonora de la presencia del poder urbano $^{11}$. Esto exige plantear la cuestión de que en estas contrataciones subyaciera el interés de la aristocracia jerezana por que la ciudad estuviera bien abastecida de unos músicos para emplear además en sus propios actos ceremoniales o festivos ${ }^{12}$.

Con todo, determinar cuál era el tipo o tipos de trompeta que tañían los trompeteros jerezanos no es tarea fácil. Aunque contamos con ejemplos como el del condestable Miguel Lucas de Iranzo, quien ya a mediados del siglo XV, disponía en su "corte musical" de Jaén tanto de trompetas naturales como bastardas o españolas, combinando, así, música militar y cortesana ${ }^{13}$, no podemos precisar si todos los trompetas municipales jerezanos poseyeron la capacidad para tocar ambas. En cualquier caso, hay que tener en cuenta que en 1541, el cabildo impone a los trompeteros municipales a utilizar la trompeta bastarda, instrumento que a los trompeteros a los que se le ordena en concreto no estaban, al parecer, especializados o "avezados"14.

Lo que sí queda de manifiesto, en cambio, es que a mediados del XVI, y en conjunción con la expansión de las nuevas prácticas musicales dentro del protocolo ceremonial ${ }^{15}$, el cabildo de Jerez emprende una clara política de renovación de sus músicos. En 1550 se acuerda aumentar el número de los trompetas, fijando su número en cuatro, con el preciso objetivo de que el conjunto de los trompetas municipales pudieran "hacer música", cosa que no era posible si sólo eran tres ${ }^{16}$. Esta última noticia evidencia el creciente papel adquirido

7 J. A. Moreno Arana, "Música...", p. 245.

8 C. Bejarano Pellicer, El Mercado..., pp. 232, 237.

9 Archivo Histórico Municipal de Jerez de la Frontera (en adelante: AHMJF), Actas Capitulares (en adelante: AC), año 1437, fol. 53v,

10 AHMJF, AC, año 1484, fol. 85.

11 C. Bejarano Pellicer, El mercado..., p. 232.

12 Ejemplos en: C. Bejarano Pellicer, El mercado..., pp. 367-368; C. Bejarano Pellicer, "La audición privada de música en España de los siglos XVI y XVII", Comercio y cultura en la Edad Moderna, Sevilla, Universidad de Sevilla, 2015, p. 1745; J. A. Moreno Arana, "Música...", pp. 243, 266.

13 C. Bejarano Pellicer, "De las alegrías...", p. 256.

14 J. A. Moreno Arana, "Música...", p. 246.

15 L. Gómez Fernández, Música, nobleza y mecenazgo. Los duques de Medina Sidonia en Sevilla y Sanlúcar de Barrameda (1445-1615), Cádiz, Universidad, 2017, pp. 74-75.

16 J. A. Moreno Arana, "Música...", p. 251. 
por la polifonía en el ceremonial público y que el aspecto heráldico de las trompetas estaba dejándose a un plano más secundario en una sociedad cada vez menos militarizada y ya imbuida en las coordenadas culturales del Renacimiento; que a los regidores les importaban la solvencia polifónica de sus trompetas se demuestra con la petición que meses más tarde, el trompeta Gaspar Sirgado haga para solicitar el aumento del sueldo de sus dos compañeros, que tañían la voz de contrabajo y de tenor respectivamente ${ }^{17}$.

En estos años, el cabildo tiene a su servicio simultáneamente a ministriles y trompetas (lo que deja fuera del debate una posible asimilación terminológica entre ambos instrumentistas), tal y como disfrutaba el cabildo sevillano ${ }^{18}$. La variedad instrumental y de repertorio que ofrecían los ministriles los convertirá en los músicos más demandados del momento. Esto hará que cabildos seculares y catedralicios, o colegiales, como en el caso jerezano, se pongan de acuerdo para cofinanciarlos ${ }^{19}$. Sin embargo, con un mercado laboral musical al alza fue difícil para el cabildo de Jerez evitar la desbandada de sus ministriles ${ }^{20}$. El afán por contar con el cualificado servicio musical que estos músicos ofrecían no será satisfecho hasta que hacia 1576, en un momento de renovación de la imagen de la ciudad promovida por los munícipes, se contrate a la copia de Juan de Saravia, que vendrá a sustituir a la figura de los trompeteros. En efecto, a Saravia se le puede relacionar con el homónimo ministril instalado en la Capilla Real de la Catedral de Granada en 1563, donde, con varios miembros de la familia Flandes, formados al servicio del ducado de Medina Sidonia, podría estar detrás de la compilación de las piezas que componen uno de los contados libros de música para ministriles que han llegado a nuestros días ${ }^{21}$.

La copia municipal de ministriles se mantiene hasta el último tercio del siglo XVII. De este modo, el último gran acontecimiento donde se emplean fueron las exequias de Felipe IV y proclamación de Carlos II (1666) ${ }^{22}$.

\subsubsection{Clarines.}

La presencia de los ministriles en las solemnidades municipales jerezanas se trunca durante el último tercio del siglo XVII, y más en concreto en 1689. En ese año, los regidores toman la decisión de prescindir de ellos por su continuada falta de asistencia por tener que atender a otros demandantes de sus servicios musicales ${ }^{23}$, especialmente al cabildo eclesiástico de la iglesia colegial jerezana, con el que los regidores mantenían una incesante pugna por la primacía en el ceremonial público ${ }^{24}$. Aparte de las ventajas

17 AHMJF, AC, tomo 17, fol. 367v.; J. A. Moreno Arana, "Música...", pp. 249, 261.

18 C. Bejarano Pellicer, El mercado..., pp. 301-304.

19 J. A. Moreno Arana, "Música...", p. 260. J. Ruiz Jiménez, "Ministriles y extravagantes en la celebración religiosa", en Políticas y prácticas musicales en el mundo de Felipe II: estudios sobre la música en España, sus instituciones y sus territorios en la segunda mitad del siglo XVI, Madrid, 2004, pp. 207-208.

20 La copia de Diego López de Morales se descompone con la deserción a Sevilla del sacabuche Juan Bautista (J. A. Moreno Arana, "Música...", p. 255). Posteriormente, ambos se asientan en la catedral de Sevilla: C. Bejarano Pellicer, Los Medina. Redes sociales y económicas en torno a una familia de músicos entre el Renacimiento y el Barroco. Sevilla, Diputación, 2019, pp. 29-30.

21 J. A. Moreno Arana, Un episodio cultural de Jerez de la Frontera en el siglo XVI. Los libros del bachiller Diego de Aguilocho, Madrid, Bubok, 2019, p. 12.

22 AHMJF, AC, tomo 68, fol. 208. AHMJF, Archivo Histórico Reservado (AHR), C. 3, N.15, fol. 39.

23 Por ejemplo, en el entierro del veinticuatro Bartolomé Dávila Núñez, en 1590, se paga cuatro ducados "a la música de San Salvador que acompañó el cuerpo": Archivo de Protocolos Notariales de Jerez de la Frontera (en adelante: APNJF), oficio 15, año 1756, 18 de marzo, fol. 59. J. A. Moreno Arana, "Música...", pp. 257-263, 265-266.

24 AHMJF, AC, tomo 78, fols. 221v-223. 
prácticas y económicas, no se puede descartar en esta decisión la intervención de los cambios que en la música asociada a la representación del poder civil se estaban gestando a nivel general ${ }^{25}$. Unos cambios que parecen buscar un tono más austero y marcial para los músicos asociados con la institución de poder civil. Un tono al que respondía a la perfección la figura del clarín, trompeta de registro agudo estrechamente unida a lo militar ${ }^{26}$.

En efecto, el 27 de junio de 1689, el cabildo resuelve serle

Más presiso para su desencia tener dos clarines que le acompañen dentro y fuera para las visitas ${ }^{27}$ y demás funciones a que suele asistir y por los açidentes de guerra que se pueden mover a que son presisas, para el servicio de las milicias y a más siendo plaza de armas destas fronteras.

Pero habrá que esperar hasta marzo de 1691 y febrero de 1692 para que los diputados de fiestas espirituales y temporales formalicen el contrato con los clarineros. El salario consistirá en cinco reales diarios, pagados de las rentas de las carnicerías, las mismas que había sostenido los cuatrocientos ducados de sueldo anual de los cinco componentes de la copia de ministriles municipales ${ }^{28}$. Los clarineros se obligaron a mantener a su costa un caballo "en que montar para las funciones que se requieran". Una exigencia que resultó excesiva. Así, Fernando Sisne y Juan Bautista Veneciano reclamarán una ayuda de cien reales anuales para cada uno para el arrendamiento de caballeriza y pajar ${ }^{29}$. Aunque el cabildo aceptó la reclamación de sus clarineros, el gasto, pese a todo, seguía siendo ventajoso para los caudales municipales con respecto a lo que les había supuesto el sueldo de los ministriles.

La situación económica no siempre fue favorable a estos músicos. En noviembre de 1750, Antonio Schubert y Francisco Garrido, que decían llevar nueve años en este ejercicio, solicitan una solución para "aliviar nuestras fatigas [...] para poder servir con el esplendor y lustre devido". Como sus inmediatos antecesores, sus franquicias habían sido tener una casa y taberna libres de todo derecho y contribuciones reales y un cornado (medio maravedí) por cada libra de carne que se cortase en las carnicerías y casas tabernas. Sin embargo, estas rentas eran precarias; pues en algunos meses apenas llegaban a rendir tres pesos. Garrido, pese a estar, como su compañero, casado y con hijos, toma rumbo hacia tierras americanas donde se le ofrecería mejores posibilidades laborales ${ }^{30}$. Otros fueron tentados por cabildos de otras ciudades del entorno ${ }^{31}$, señal de la alta demanda que existía de estos intérpretes. Aunque los caudales municipales financien el arrendamiento de sus viviendas, la situación no mejorará; en 1786 el sueldo eran unos cortos cinco reales diarios $^{32}$, no ayudando las "gratificaciones" por la asistencia a determinados festejos o

25 C. Bejarano Pellicer, El mercado..., pp. 231.

26 El debate sobre las distintas trompetas y su uso: B. Kenyon de Pascual, "Clarines and trompetas: some further observations", Historic Brass Society Journal, 7, (1995), pp. 100-105; V. Alcaide Roldán, "La influencia de la escuela italiana de trompeta en la corte española de Felipe II", Revista AV Notas, 6, (2018), pp. 32-54.

27 En 1796, los capitulares jerezanos van a Sevilla a invitar al rey Carlos IV a que visitara la ciudad acompañados de los clarineros, quienes montados a caballo, con el resto de la comitiva capitular, se presentan ante el monarca tocando "su acostumbrada marcha": AHMJF, legajo 301, expediente 8955.

28 J. A. Moreno Arana, "Música...", p. 261.

29 AHMJF, AC, tomo 78, fol. 922v.; AHMJF, AC, tomo 79, fols. 456-457, 581, 903, 906, 908.

30 AHMJF, AC, tomo 97, fols. 643- 759-760, 836; AC, tomo 98, fol. 508. AHMJF, AHR, C. 18, N. 34, fol. 256.

31 AHMJF, AC, tomo 122, fol. 454.

32 AHMJF, AHR, C. 16, N. 26; AHMJF, AC, tomo 124, fols. 53, 96, doc. 18, 41. 
ceremoniales públicos, como los juegos de alcancías en los tres días de Carnaval ${ }^{33}$ o las honras fúnebres reales ${ }^{34}$.

\subsection{Contrataciones de músicos para determinados eventos.}

La variedad de repertorio de los ministriles les permite asumir durante más de dos siglos toda la actividad ceremonial o de representación en el espacio urbano que requería de la música instrumental de viento. En ciertas ocasiones, como podía ser la publicación de bandos o los desfiles de la comitiva municipal, tanto trompetas como ministriles se acompañaban con la percusión de atambores o de atabales que, según la época, eran contratados puntualmente por el cabildo o bien formaban parte de la nómina municipal ${ }^{35}$.

Sin embargo, habiendo quedado la figura de los músicos municipales jerezanos reducida desde fines del siglo XVII a la de los dos clarineros, cuya función principal se limitó a la de ser heraldo del poder civil, el cabildo precisará otros conjuntos musicales que se adapten a cada escenario ceremonial. Así, la primera noticia que tenemos de la participación de músicos ajenos a la nómina municipal la encontramos en el acto de proclamación de Luis I, en 1724. Junto a los clarines, sabemos de la presencia de oboes, timbales y "otros instrumentos militares" ${ }^{36}$. En la proclamación de Fernando VI, en 1746, ya se constata "un concierto de dulces instrumentos ${ }^{37}$ y caxas militares" dado en las tres tardes de fiesta en el theatro colocado delante de las casas capitulares. El "agasajo que han de haber los que compusieren los conciertos de dulces instrumentos" se incluye dentro de los 22.350 reales de vellón en que se valoró el gasto de todo el entramado montado en la plaza. El costo total de la ceremonia de proclamación ascendería a 144.900 reales $^{38}$. En 1759 , al acto de la lectura de la real orden de proclamación de Carlos III concurren una orquesta de "instrumentos de cuerda", los clarines y timbales del Regimiento de Caballería del Príncipe y los "instrumentos de boca" del Regimiento de Dragones de la Reina. Una variedad de conjuntos instrumentales que intervienen en el acto de manera alternante y policoral tan del gusto de la época ${ }^{39}$. En 1789, en el desfile de alzamiento del pendón por Carlos IV actúan, asimismo, varias bandas militares. Según las relaciones impresas, fueron "las bandas de música de los batallones y brigadas de la Real Armada y la de la profesión de caballeros guardias marinas, todos a caballo". La presencia de estas concretas bandas militares, así como también la de la banda de música de la Real Maestranza de Ronda, hay que relacionarla con la vinculación de miembros de la oligarquía jerezana con estas instituciones de marcado carácter nobiliario. Según el acta de cabildo, la "banda de tambores, pífanos y clarinetes" del regimiento de milicias instalado en la ciudad participó en la lectura del bando que informaba de las inminentes celebraciones. En efecto, las cuentas municipales de fines de siglo documentan el pago a los pífanos, clarinetes y tambores del regimiento provincial de Jerez por solemnizar la lectura de los distintos bandos municipales ${ }^{40}$. El regimiento

33 En el carnaval de 1754 su asistencia es retribuida con 20 reales para cada uno. Apenas un $8 \%$ del gasto total: AHMJF, AC, tomo 98, fols. 419-420.

34 AHMJF, Legajo 301, expediente 8958.

35 J. A. Moreno Arana, "Música...", pp. 244-245; AHMJF, AHR, C. 16, N. 24.

36 AHMJF, AC, tomo 90, fol. 286v.

37 Oboe, flauta, clarinete y quizás también algún instrumento de cuerda.

38 A ello había que incluir los gastos de las exequias, que se ajustaba en 25.345 reales. AHMJF, AC, tomo 96, fols. 296-297, 470.

39 M. Díez Martínez, La música en Cádiz: la catedral y su proyección urbana, Cádiz, Universidad de Cádiz, 2004, p. 66.

40 AHMJF, AHR, C. 16, N. 25; AHMJF, AHR, C.16, N. 26. 
provincial de milicias de Jerez se crea en $1734^{41}$. En 1753 , únicamente consta entre sus filas el tambor mayor y ocho tambores ${ }^{42}$, por lo que la incorporación de los instrumentos de viento, como el pífano y el clarinete, dentro de la infantería jerezana tuvo que ser posterior a dicha fecha y debida a las ordenanzas reales publicadas en las décadas de 1750 y $1760^{43}$.

La música militar no podía satisfacer, por sus propias limitaciones instrumentales y de repertorio, todos los escenarios de los fastos públicos. En la visita del embajador de Marruecos, El Gazzal ${ }^{44}$, en junio de 1766, se agasaja con dos corridas de toros en la plaza mayor del Arenal acompañadas con una "opulenta orquesta de música que delante de su balcón repetía conciertos ${ }^{45}$ ". Las orquestas contratadas se compusieron tanto por músicos de la propia ciudad, como traídos de los grandes centros musicales del entorno más cercano, es decir, Sevilla y Cádiz, un refuerzo de efectivos musicales que fue bastante habitual incluso en esas mismas capitales ${ }^{46}$ y subraya la preocupación por contar con grandes efectivos musicales para esto eventos. De este modo, cincuenta y seis músicos, "de la mayor destreza de Cádiz" y de Jerez, fueron los llamados para las celebraciones que en 1784 se realizan por el nacimiento de los infantes gemelos y la Paz con Inglaterra ${ }^{47}$.

Más concreción tenemos de los músicos contratados para los actos de la visita de Carlos IV y su familia a Jerez en 1796. En las cuentas de gastos formadas a raíz de la estancia real se consignan las "dos capillas de Música que vinieron a esta ciudad"48. Se relaciona, así, una "lista de los quarenta individuos que con la determinación de los señores deveran asistir a las funciones en la ciudad de Xerez": catorce violines (Jerónimo Rosquellas, Francisco Rosquellas, Fernando Ferrandiere, Lorenzo Bruroni, Esteban Lepiani, José Riguert, Salvador Camerino, Jácome Castañeto, Jácome Lepiani, Juan Salvo, Juan Ricer, Joaquín Tomati, Victorio Tinareli, Juan Lunar); seis oboes y flautines (Carlos Climan, Antonio Climan, Juan Climan, Pedro Capdevila, Antonio González, Juan Carbo); siete contrabajos (Juan Castro, José Molina, Pascual Vega, “D. Francisco y D. [¿?]”, Juan Lavan, Clemente Cleman); dos timbales (Tomás Abril y José Vega); dos violas (Isidro Laporta y José Lepiani); cuatro trompas (Juan Peregrín, Antonio Capdevila, Andrés Capdevila y Joaquín Castro); cinco clarines (Juan Lepiani, Rafael Castro, José Lepiani, Luis Moreno y Juan Gonela). Se contabiliza un coste de 1.400 reales. No se puede precisar si todos ellos formaban esas dos orquestas que citan las cuentas, ni si en esta lista estaban incluidos los "músicos de Sevilla" que participaron en las funciones ecuestres ${ }^{49}$.

Esta interesante lista de músicos, aparte de señalar la procedencia italiana y del Levante español de sus apellidos y de mostrar, una vez más, la endogamia que caracterizaba al oficio de músico, así como de dar una exacta descripción de la composición de estas orquestas, permite conocer el currículo de los músicos elegidos; violinistas como,

41 AHMJF, AC, tomo 92, fol. 628.

42 AHMJF, AC, tomo 98, fols. 155-158.

43 B. Arredondo, Entre pitos y flautas: El músico Manuel Espinosa y su legado (1730-1810), Amazon, 2020, capítulo 1.

44 T. García-Figueras, "La embajada de 'El gazzal' (1766)", África. Revista de estudios hispano-africanos. Segunda época, mayo (1936), pp. 86-89.

45 El término "concierto" es utilizado como sinónimo de actuación instrumental. El debate terminológico en: H. Santos Conde, "Definiciones y usos del término 'concierto' en la documentación catedralicia española", Resonancias, 23, (2019), pp. 13-35.

46 M. Díez Martínez, La música en Cádiz..., pp. 66, 211.

47 F. Aroca Vicenti, Arquitectura y urbanismo en el Jerez del siglo XVIII, Jerez, CUES, 2002, pp. 266, 277.

48 AHMJF, Legajo 301, expediente 8964.

49 AHMJF, Legajo 301, expediente 8964. El alquiler de los caballos para los músicos se tasó en 614 reales. 
Rosquellas, Bruzoni, Ferrandier, De la Vega, Castañeto y Tomati habían estado al servicio de la Catedral de Cádiz ${ }^{50}$. Pero además, algunos de ellos (la familia Capdevila, y los citados Rosquellas, Ferrandier y Tomás Abril) trabajan asimismo para la "música teatral"51. Esta elección de estos concretos músicos habría que relacionarla con una meditada búsqueda de intérpretes y repertorios que respondieran a las necesidades de aparato teatral de estas fiestas públicas, y quizás también con el gusto por un género en apogeo en aquellos años.

\section{ESCENARIOS PARA LA REPRESENTACIÓN SONORA DE LA OLIGARQUÍA LOCAL}

Los contratos que los músicos formalizan con el ayuntamiento jerezano durante los siglos XVI al XVIII son documentos de gran interés para establecer los contextos que dan lugar a la utilización de lo sonoro como parte de la escenificación del poder oligárquico local ${ }^{52}$. Dejando a un lado las celebraciones ordinarias, la solemnidad pública en la que se integra la música podía tener diversos desencadenantes, algunos tan puramente domésticos como el casamiento en 1657 de la prima del corregidor con un noble jerezano ${ }^{53}$; el fallo favorable para la restitución de tierras baldías de la ciudad en 165754; la visita del Duque de Maqueda en $1615^{55}$ o la del arzobispo en $1650^{56}$. Pero también otros de índole más general, caso de victorias militares de los ejércitos españoles, como en Fuenterrabía en 163857; desagravios por herejías cometidas en Flandes en 1635 58 ; o la elección del papa de Sixto $\mathrm{V}$ en $1584^{59}$. Pero fueron los acontecimientos relacionados con la monarquía donde se vuelcan todos los esfuerzos del gobierno local y de sus miembros para hacer "demostración" de su adhesión a su proyecto político. Un poder real del que dimanaba la propia potestad de los regidores locales.

Estas "demostraciones" no se pueden desligar, por otro lado, del elemento propagandístico que se alienta con la emulación. En nuestro caso, desde fechas muy tempranas observamos la forzada repetición del aparato ceremonial de otras ciudades de rango superior, como modo de alimentar el prestigio de la ciudad. Así sucede en 1454 cuando el duque de Medina Sidonia escriba a Jerez informado de los actos realizados en Sevilla por la muerte del rey don Juan y proclamación de Enrique IV, donde la música tuvo un remarcado papel, y que a su vez repetían los realizados en esa ciudad por anteriores reyes $^{60}$. Una emulación que ilustra el regidor de orígenes genoveses Lorenzo Adorno cuando relata a sus compañeros, en 1567, "que se hacían fiestas en Granada y en todas partes por el parto de la reyna" y que Jerez también se debía sumar a ellas, "de suerte que

50 M. Díez Martínez, La música en Cádiz..., pp. 54, 56, 208-209.

51 P. Bolaños, "Comedias y comediantes en el coliseo de Écija (1772-1774)", en Teatro español del siglo XVIII: Tomo I y II, Lleida, Universidad, 1996, p. 123; A. Romero Ferrer y A. Moreno Mengíbar, Manuel García: De la tonadilla escénica a la ópera española (1775-1832), Cádiz, Universidad de Cádiz, 2006, pp. 36-39.

52 J. A. Moreno Arana, “Música...", pp. 264-265.

53 AHMJF, AC, tomo 64, fol. 1051.

54 AHMJF, AC, tomo 64, fol. 197rv.

55 AHMJF, AC, tomo 43, fol. 1544v.

56 AHMJF, AC, tomo 60, fol. 224.

57 AHMJF, AC, tomo 52, fol. 330.

58 AHMJF, AC, tomo 50, fol. 968.

59 AHMJF, AC, tomo 28, fol. 70.

60 AHMJF, AC, año 1454, fol. 47v. 
se entienda el contento que tenemos por el buen alumbramiento"61. Ya en el siglo XVIII, hay que referir el caso de la visita de Carlos IV, donde se tomará como referencia lo actuado en la visita de Felipe $\mathrm{V}$ y su familia a Jerez en 1729, así como una publicación referida a su estancia sevillana ${ }^{62}$.

A continuación repasamos los escenarios ceremoniales en los que se van a poner en práctica la representación del poder municipal jerezano a través de la música.

\subsection{Pregones y bandos.}

El acto ceremonial estaba precedido por el bando que comunicaba su celebración. En 22 de octubre de 1567, por ejemplo, se pregonan las fiestas por el buen parto de la reina "públicamente tocando las trompetas en la plaza de san Dionis", espacio principal de representación de la ciudad al estar allí ubicadas las casas consistoriales. La función de las trompetas en estas ocasiones era la de ir andando por la ciudad junto a los pregoneros "regocijando a la gente" 63 . Del mismo modo, el 10 de agosto de 1789, la proclamación de Carlos IV se anuncia por los lugares principales de la ciudad por los dos clarineros municipales a los que seguía, en este caso, la "banda de tambores, pífanos y clarinetes" del regimiento de milicias ${ }^{64}$. En el caso opuesto, el fallecimiento real, son las campanas de las iglesias las que rompen el silencio que durante el luto se impone sobre la ciudad, rompiendo el paisaje sonoro y musical cotidiano, como sucede, por ejemplo, en 1568 con la muerte de la reina Isabel de Valois ${ }^{65}$. Y cuando la música interviene, lo hace de forma atenuada, como en la publicación de las exequias por Fernando VI o en las de la reina de Portugal (1756), donde la música del regimiento de milicias irá con sordinas y con enlutados en los tambores ${ }^{66}$.

\subsection{El desfile festivo. Las mascaradas.}

El anuncio de los regocijos también se llevó a cabo mediante desfiles a caballo protagonizados por los nobles locales. En 1657, la noticia de un natalicio real llevó a los nobles, de dentro y fuera del ayuntamiento, a ponerse "de gala a caballo" y recorrer las calles y plazas en señal "de festexo y alegría". Fueron asistidos por la música de los ministriles ${ }^{67}$. Este mismo ritual se repite en 1707 con el nacimiento del Príncipe de Asturias, aunque aquí fueron los dos clarines los que acompañan al cortejo ${ }^{68}$.

Estos desfiles coreográficos fueron un recurso usual en la fiesta barroca en el orbe hispánico ${ }^{69}$. En 1605, el cabildo financia una "mascara" por el nacimiento del príncipe. Los diputados de fiestas convidarían "a sesenta caballeros de dentro de este cabildo y de fuera de él y den las hachas que fueren necesarias", ordenándose asimismo que se diera "las

61 AHMJF, AC, tomo 23, fols. 480v. 481.

62 AHMJF, Legajo 301, expediente 8963.

63 AHMJF, AC, tomo 21, fols. 480v., 482; AC, tomo 22, fol. 562v.

64 AHMJF, Legajo 301, expediente 8961.

65 Se ordena que ninguna persona tocase "vihuelas", "adufes", "panderetes", "sonajas" ni cantara durante un mes bajo la pena de perder el instrumento: AHMJF, AC, tomo 23, fols. 998-998v.

66 AHMJF, Legajo 301, expediente 8955; AHMJF, Legajo 301, expediente 8958, fol. 7.

67 AHMJF, AC, tomo 64, fols. 339v-240v.

68 T. de Vílchez Ávila y Ochoa, Breue relacion en que se da cuenta de las fiestas... con que la ... ciudad de Xerez de la Frontera ha celebrado el ... natal de el ... Príncipe de Asturias, Cádiz, 1707, p. 6

69 C. Bejarano Pellicer, "Los festejos por el nacimiento de un príncipe: el papel de la música y la danza", en Congreso Internacional Andalucía Barroca. Actas de la sección III: Literatura, Música y Fiesta, Sevilla, Junta de Andalucía, 2009, tomo III, pp. 245-252. 
libreas a los atabales y ministriles"70. Con motivo de la conquista de la Mamora, en 1614, los regidores organizan una "máscara e paseo por la ciudad en muestra de alegría llevando los ministriles delante, y a cada caballero una hacha de cera con que se alumbre"71.

En 1789, la mascarada, ya como desfile de danzantes disfrazados, tan propias de las celebraciones del Corpus, tendrá un papel principal en los festejos por la proclamación de Carlos IV, con la evidente voluntad de identificar a ambas "Majestades". Pero cabe asimismo una interpretación asociada al ensamblaje de la idea sobre los supuestos orígenes romanos de Jerez. Una idea que el cabildo, junto con sus publicistas, quiso imprimir a esta celebración ${ }^{72}$. Este "cortejo triunfal" se compuso de "dose quadrillas de mascaras compuestas de ciento y noventa y dos hombres" caracterizados de diferentes naciones, etnias y épocas: "bailando cada cuadrilla sus diferentes danzas, mandadas todas por dos maestros, uno vestido a la inglesa y otro a la francesa con sus bastones en la mano"73.

\subsection{Desfiles fúnebres.}

La disminución o la total desaparición sonora caracterizan al ceremonial fúnebre escenificado en el espacio público urbano mediante el desfile de la comitiva municipal a la iglesia donde se realizarán las honras o exequias. En las honras por Carlos II, el cortejo lo abría la compañía de la milicia con los "tambores tocando las cajas destempladas cubiertas de negro". Detrás seguían "dos sordinas negras y los que las tocaban (los clarineros) con unos sayos ropones de bayeta negra" 74 .

El conjunto de ministriles municipales también había participado en estos cortejos fúnebres; constan sus peticiones de ayuda al cabildo para comprar los lutos que exigía el decoro del ceremonial ${ }^{75}$. No obstante, no hay constancia de que ejercieran una actividad musical dentro de la comitiva. Su presencia, como menos, pudo reducirse a la de actuar como simple emblema del poder. En otras palabras, un silenciamiento de la "vanitas sonora" de los regidores como sublimación pública de su duelo ${ }^{76}$.

\subsection{Acto de proclamación del nuevo rey.}

Este momento culmen del ritual festivo público apenas varía en sus líneas generales desde el siglo XV. El acto comenzaba con la lectura pública de la real cédula de traspaso de la corona. La música tiene aquí su primer momento para el énfasis ceremonial. En la proclamación de Felipe III, en 1598, son los ministriles municipales acompañados de la percusión militar los que tuvieron el protagonismo musical:

E leida e pregonada la dicha cedula real la ciudad por la horden con los alguaziles y porteros del cavildo con sus rropas largas de armas colorados e sus masas de plata delante y los ministriles e atabales se fue a la yglessia del señor sant salvador y apeados de sus cavallos la ciudad entró dentro de la dicha ygleçia.

70 AHMJF, AC, tomo 38, fol. 971v.

71 AHMJF, AC, tomo 42, fol. 1411.

72 Descripción analítica..., s/p. La raigambre clásica de las mascaradas en: F. Ollero Lobato, F., "Las mascaradas, fiesta barroca en Sevilla", Potestas, 6, (2013), p. 145.

73 AHMJF, Legajo 301, expediente 8961.

74 AHMJF, AHR, C. 8, N. 15, pp. 45-46.

75 AHMJF, AC, tomo 37, fol. 957v.; AHMJF, AHR, C. 3, N.15, fol. 39.

76 C. Bejarano Pellicer, "El paisaje sonoro fúnebre en España en la Edad Moderna: el caso de Sevilla", Obradoiro de Historia Moderna, 22 (2013), p. 256. 
Llegados a la iglesia colegial, el alférez mayor recibía en pleito homenaje el pendón real allí custodiado. Este momento álgido se enfatiza por los "músicos e cantores e cleressia" de la iglesia mayor y "se dixo e cantó en mussica bosses altas el ynno y cantico de te deun laudamus". Con el histórico estandarte, los regidores volvían a la casa capitular para desde allí dirigirse a tomar el alcázar en nombre del nuevo rey, "yendo delante los atavales y ministriles tañendo hasta llegar a la puerta del castillo y alcasar desta ciudad"77.

La corporación municipal iba "en forma de ciudad", montada a caballo, para remarcar la solemnidad del acto. Esto no excluía a los músicos, quienes, si bien no toda la copia, también ejercían su labor desde lo alto de la montura. En efecto, en los actos de proclamación de Carlos II se alquilan cinco caballos "para los atabales y algunos de los ministriles que se ocuparon el domingo en la tarde deste presente mes que asistieron a la publicación de alsar el pendón por su magestad"78. De igual manera se repite en la de Felipe $\mathrm{V}^{79}$.

En 1454, fecha de entronización de Enrique IV, el pendón lo custodiaba el alcaide del alcázar. El escribano de cabildo subraya que dicho acto se efectuó "tocando trompetas e atabales y otros sonidos de menestriles"80. Tras el alzamiento del pendón, la comitiva local a caballo portando la insignia se dirige a la plaza de San Dionís para desde allí recorrer "las calles maestras desta cibdad por donde se acostumbra llevar el cuerpo del señor", reforzando con este ritual urbano la idea de la analogía entre el poder temporal y el poder celestial. Toda la ciudad irá jurando al nuevo rey bajo los sonidos de las "trompetas e atabales e otros ministriles".

En el alzamiento del pendón real por Carlos I no se llevó a cabo la parte de la toma del alcázar, pero la presencia de "las trompetas et atabales desta ciudad" seguirá siendo inexcusable ${ }^{81}$.

En el siglo XVIII, la evolución de las prácticas musicales hacen que en la proclamación de Carlos IV se cuente con "una cumplida orquesta de música", con la que se buscó captar la atención del público con una "gran confusión de ecos sonoros de clarines, abues, tronpas y otros instrumentos". La descripción analítica de este evento describe un teatro dispuesto para una orquesta de "veinticuatro instrumentos" situado delante de la renacentista fachada de las casas capitulares, concebida a la manera de clásico frons scenae para estas intervenciones sonoras. Este mismo cuadro se repite en las proclamaciones de Luis I, Fernando VI y Carlos III ${ }^{82}$.

\subsection{Espectáculos ecuestres.}

Siendo Jerez una ciudad generalmente conocida por la crianza y habilidad en el manejo de los caballos por parte de su nobleza ${ }^{83}$, resulta lógico que los espectáculos ecuestres acaparasen el programa festivo. En los juegos de cañas descritos en la relación impresa de las fiestas por el nacimiento del infante Baltasar Carlos, en 1630, el "primer son de la trompeta" era el aviso para la entrada de los jugadores ${ }^{84}$. El tratadista Fernández de

77 AHMJF, AC, tomo 36, fol. 941. Idénticas fueron las de Felipe IV y Carlos II: AHMJF, AC, tomo 41, fols. 132v-137v.; AC, tomo 58, fol. 208-224.

78 AHMJF, AHR, C. 3, N. 16, fol. 54.

79 AHMJF, AHR, C. 8, N. 15, pp. 45-46.

80 AHMJF, AC, año 1454, fol. 48v.

81 M. Romero Bejarano, Los orígenes de la Semana Santa de Jerez, Jerez, 2019, pp. 97-98.

82 AHMJF, AC, tomo 90, fol. 286v.; AHMJF, AC, tomo 98, fols. 155-158; AHMJF, AHR, C. 3, N. 91.

83 P. Fernández de Andrada, De la naturaleza del Caballo, Sevilla, 1580, fols. 51v, 74v y 138v.

84 J. Spínola y Torres, Descripción de la fiesta de cañas y toros celebradas en Jerez de la Frontera en 1630 con motivo del Nacimiento de príncipe D. Baltasar Carlos, Madrid, 1916, p. 19. 
Andrada al referirse al desarrollo de los juegos de cañas incide en que el acompañamiento de "ministriles y otros instrumentos de librea" era muestra de "ostentación y autoridad", además de tener la función de "regocijar" la entrada de las cuadrillas y de alentar a los caballos $^{85}$. En efecto, en las fiestas por los catorce años de Carlos II, en 1676, se hace referencia a las "salva de los clarines dando aviso como entravan los señores"86.

En estos teatrales espectáculos, la música tiene un papel que experimenta una presencia cada vez más visible, que habría que relacionarla con la sustitución de los bélicos juegos de cañas por las distintas habilidades con el caballo, y por ello más a propósito, por su elemento coreográfico, para ser acompañados por la música. Enriquecido con la evolución de unas prácticas musicales caracterizada por la adición de elementos, lo sonoro llega al culmen del paroxismo en las funciones diseñadas para la proclamación de Carlos IV. En ellas van a participar dos orquestas dispuestas en lugares separados de la plaza mayor del Arenal, dentro del coso o "coliseo" montado para la realización de los juegos. La principal de estas formaciones se componía de "cuarenta y seis músicos, con instrumentos de viento y cuerda". La otra se acomodó en el segundo cuerpo de un triunfo erigido en un lateral de la plaza donde se colocaron los danzantes de la mascarada, realizando "bien ordenadas y diestras contradanzas, y otros géneros de bayles". Durante el festejo ecuestre interviene la orquesta del trono. En sus intermedios, sin embargo, participan a la vez ambas orquestas junto con los danzantes, dando muestra del policoralismo, recurso que intensificaría la teatralidad de las funciones ${ }^{87}$.

Más detalles de cómo actúa la música en estos espectáculos los ofrece la relación de las fiestas por el nacimiento de los infantes en 1784; la "comparza de caballeros" llega a la plaza "asistida de tropa montada con su correspondiente música". En los festejos por la proclamación de Carlos IV, esta entrada se realiza con el acompañamiento de los clarineros y la banda de música de la Real Maestranza de Ronda, todos a caballo ${ }^{88}$. En 1784, al llegar al lugar del trono presidido por el retrato del monarca se oyeron "armoniosos rumores de los instrumentos músicos y aclamaciones de viva el rey". Mientras tenían lugar los distintos lances prosiguieron "incesantes las horquestas con oberturas de diferentes cadencias". En el momento en que los caballeros "mudaban caballos, y se disponían para las alcancías" la música no paró de sonar ${ }^{89}$.

Los honorarios de "Los músicos de Sevilla" que participan en las funciones ejecutadas en la visita de Carlos IV en 1796 fueron pagados a mitad entre el cabildo municipal y los nobles participantes en ellas. La cifra ascendió a 11.220 reales, más 614 reales del alquiler de los caballos para los músicos, lo que supuso el 10,7\% de los gastos ocasionados ${ }^{90}$.

\subsection{El día de fiesta por la noche: iluminación, fuegos artificiales y recepciones públicas.}

Acabadas estas funciones ecuestres, con la puesta del sol, comenzaba la iluminación efímera de la ciudad, a la vez que se abrían los distintos convites o refrescos que tanto

85 P. Fernández de Andrada, De la naturaleza..., p. 135.

86 G. Mercado y Mendoza, Relevantes demostraciones con que la nobilíssima ciudad de Xerez de la Frontera manifestó en obsequios su lealtad y amor en festivos aplausos al cumplimiento de los catorze y felices años de el rey nuestro señor D. Carlos Segundo. Jerez de la Frontera, 1676.

87 Otros casos en: C. Bejarano Pellicer, El mercado..., p. 297.

88 Descripción analítica de las magnificas funciones que hizo... Xerez de la Frontera... con... motivo de la... proclamación... Carlos IV, Jerez, 1790, p. 46.

89 Manifiesto descriptivo de las demostraciones... Xerez de la Frontera celebraron... del nacimiento de los dos infantes gemelos... y paz con Inglaterra, Puerto de Santa María, 1784, pp. XII-XIII.

90 AHMJF, legajo 301, expediente 8964. 
el ayuntamiento como algunos nobles en particular ofrecían a sus invitados, donde la audición privada de música también tuvo su lugar. La transformación lumínica de la ciudad se acompaña generalmente de conciertos. En los siglos XVI y XVII, los ministriles tuvieron la obligación de tañer en estos momentos de la noche en las torres de la muralla que daban a la plaza mayor ${ }^{91}$. En el siglo XVIII serán las grandes orquestas las que prolongan sus conciertos desde este momento y durante el tiempo que duran los "refrescos"92. El escribano de cabildo que relata la proclamación de Carlos III expone que estos conciertos se enfocaban a dos fines principales: el primero, al "divertimiento del pueblo", evitando desordenes públicos ${ }^{93}$. El otro, y quizás el principal, a la "concurrencia a la vista del retrato de S.M."94. En las cuentas de gastos formadas a raíz de la estancia real en Jerez en 1796, se anota la contratación de "dos capillas de Música que vinieron a esta ciudad y concurrieron a las orquestas delante del balcón real, en el de la ciudad (durante los festejos en la plaza del Arenal) y a la noche en el salón y sala capitular".

\subsection{Recepción pública de personalidades que visitan la ciudad.}

El ambiente sonoro en estas recepciones va a ser siempre militar. Se constata en la visita del arzobispo en $1650^{95}$. O cuando la corporación local, nuevamente a caballo, salga al encuentro de la comitiva real de Carlos IV. En esta ocasión, el cortejo municipal lo encabezaba una "comparsa de músicos con instrumentos de viento y timbales en decentes enjaezados caballos tocando marcha". Tras ello, los "dos clarines de la ciudad con uniformes nuevos galoneados con sus vandoleras en los clarines bordadas montados en decentes enjaezados caballos". Este aire marcial repite el del recibimiento dado al embajador de Marruecos en 1766, donde interviene la Compañía de Granaderos del regimiento de Dragones del Rey "y en su correspondiente sitio la música" 96 tocando la marcha perteneciente al citado cuerpo militar de infantería, la hoy conocida como "Marcha Real".

Volviendo a la visita de Carlos IV, al avistarse la llegada de los coches de la comitiva "hubo repique general de las campanas de las iglesias y la música comenzó su marcha", completándose así el característico paisaje sonoro festivo urbano. La música militar acompañará a la comitiva real en cada salida que realice de la ciudad en los días que estará albergada en ella ${ }^{97}$.

\section{CONCLUSIONES}

La ciudad de Jerez de la Frontera ha aportado al estudio de la musicología urbana una serie de referencias para seguir acotando geográfica y temporalmente la fenomenología referida a la simbiosis entre música y poder civil durante la Edad Moderna. El análisis de los contextos de la solemnidad pública ha puesto de manifiesto que la música no sólo interviene para dar autorización sonora a la potestad municipal, sino que también funciona como pieza para una construcción ideal de la urbe y su gobierno. Esta idealización a través

91 J. A. Moreno Arana, "Música...", p. 265.

92 Descripción analítica..., p. 41; Manifiesto descriptivo..., pp. XIII y XIV; M. J. de la Torre Molina, Música y ceremonial en las fiestas reales de proclamación de España e Hispanoamérica (1746-1814), tesis doctoral de la Universidad de Granada, 2003..., pp. 281-291.

93 Descripción analítica..., p. 41.

94 AHMJF, legajo 301, expediente 8955.

95 AHMJF, AC, tomo 60, fol. 224.

96 T. García-Figueras, “La embajada...", p. 87.

97 AHMJF, legajo 301, expediente 8963. F. Aroca Vicenti, Arquitectura..., p. 259. 
de lo sonoro llega incluso a modelar espacios y edificios, tanto de forma efímera como permanente ${ }^{98}$. El cambio de los trompetas por el conjunto de ministriles o el de éstos por el de los clarines no se puede deslindar de esa política de idealización de la ciudad jerezana, ni de los cambios mentales que tienen lugar en cada momento. Ni tampoco, lógicamente, de la natural evolución de los instrumentos y de los gustos musicales. Sin embargo, pese a que las formas puedan variar a lo largo de este amplio periodo, el ritual urbano y el fondo de la intervención de la música en este permanecen invariables. Desde momentos medievales, en Jerez se consolidan unos concretos espacios y ritos urbanos en los que la música o lo sonoro tienen una ineludible participación ceremonial ${ }^{99}$. De este modo, la sonoridad militar está íntimamente relacionada con los contextos celebrativos del poder civil y real desde el Medievo. Propiciadora del sentimiento de exaltación patriótica, de identificación con el régimen político y de cohesión social, la música militar, en especial en las solemnidades de carácter áulico, adquiere un claro protagonismo, sobre todo con la formación de las bandas de música militares a lo largo de la segunda mitad del siglo XVIII ${ }^{100}$. Acompañando a los sones marciales y de tintes caballerescos, la música instrumental profana va a ir progresivamente tomando nuevas complejidades en estos rituales festivos hasta culminar en las grandes orquestas que inauguran una nueva sonoridad no menos efectiva para "excitar los espíritus" del pueblo, tal y como denuncia el padre Feijoo con respecto a la introducción del violín en las capillas catedralicias ${ }^{101}$. En este sentido, habría que valorar el efecto emulador que pudo dar lugar en la región el fasto ceremonial y la brillantez musical ligada con la corte sevillana de Felipe $\mathrm{V}^{102}$.

Aunque el cabildo jerezano no dedicó un presupuesto especialmente abultado para la construcción y propaganda de la imagen de la ciudad, así como para forjar alianzas políticas con otras instituciones o casas nobiliarias, a través de la música ${ }^{103}$, este mecenazgo musical sí enriqueció de forma notable el paisaje sonoro y cultural de la ciudad. Y es que la fiesta, y por extensión la música, por encima de ser una herramienta política, era un fin en sí misma. Los propios capitulares, en relación al "buen alumbramiento" de la reina en 1566, lo dejaron por escrito: "es justo que todos los vasallos de su magestad nos regocijemos corporal y espiritualmente"104. Y así lo acordaron.

\section{BIBLIOGRAFÍA}

Alcaide Roldán, V., "La influencia de la escuela italiana de trompeta en la corte española de Felipe II", Revista AV Notas, 6 (2018), pp. 32-54.

Arredondo, B., Entre pitos y flautas: El músico Manuel Espinosa y su legado (1730-1810), Amazon, 2020.

98 I. Fenlon, "La Magnificencia como imagen civil: música y espacio ceremonial en Venecia a principios de la Edad Moderna", en Música y cultura urbana, Valencia, PUV, 2005, pp. 193-218. Baker, G., "La ciudad sonora: Música, fiesta y urbanismo en el Cuzco colonial", en La fiesta en la época colonial iberoamericana, Bolivia, 2008, Asociación Pro Arte y Cultura, pp. 49-71.

99 En este sentido: C. Bejarano Pellicer, "De las alegrías medievales...”, pp. 242-267; C. Bejarano Pellicer, "El paisaje sonoro de la ciudad de Sevilla en las fiestas públicas de los siglos XVI y XVII", en Paisajes sonoros medievales. Mar del Plata. Universidad Nacional Mar del Plata. 2019, pp. 113-138.

100 M. J. de la Torre Medina, Música..., p. 104. B. Arredondo, Entre pitos..., capítulo 1.

101 M. Díez Martínez, La música en Cádiz..., p. 209.

102 M. Gembero-Ustárroz, "Importancia de la visita de Felipe V. El contexto musical andaluz durante la estancia de la corte de Felipe V en Sevilla (1729-33)", en Sevilla y Corte. Las artes y el Lustro real (17291733), Madrid, Casa de Velázquez, 2010, pp. 305-306, 308-310.

103 Por ejemplo, con la Casa de Medina Sidonia: AHMJF, AC, tomo 45, fol. 677, AHMJF, AC, tomo 38, fol. 60. 104 AHMJF, AC, tomo 22, fol. 562. 
Aroca Vicenti, F., Arquitectura y urbanismo en el Jerez del siglo XVIII, Jerez, CUES, 2002.

Baker, G., "La ciudad sonora: Música, fiesta y urbanismo en el Cuzco colonial", en La fiesta en la época colonial iberoamericana, Bolivia, Asociación Pro Arte y Cultura, 2008, pp. 49-71.

Bejarano Pellicer, C., "De las alegrías medievales a las solemnidades barrocas: las raíces del paisaje sonoro festivo de la España moderna en la crónica del condestable Miguel Lucas de Iranzo", en Paisajes sensoriales, sonidos y silencios de la Edad Media. Mar del Plata, Universidad Nacional de Mar del Plata, 2016, pp. 242-267.

- "La audición privada de música en España de los siglos XVI y XVII", en Comercio y cultura en la Edad Moderna, Sevilla, Universidad de Sevilla, 2015.

- "Los festejos por el nacimiento de un príncipe: el papel de la música y la danza", en Congreso Internacional Andalucía Barroca. Actas de la sección III: Literatura, Música y Fiesta, Sevilla, Junta de Andalucía, Consejería de Cultura, 2009, pp. 245-252.

- "El paisaje sonoro fúnebre en España en la Edad Moderna: el caso de Sevilla", Obradoiro de Historia Moderna, 22, (2013), pp. 249-282.

- El mercado de la música en la Sevilla del Siglo de Oro, Sevilla, Universidad de Sevilla, 2013.

- $\quad$ "El paisaje sonoro de la ciudad de Sevilla en las fiestas públicas de los siglos XVI y XVII", en Paisajes sonoros medievales, Mar del Plata. Universidad Nacional Mar del Plata, 2019, pp. 113-138.

- Los Medina. Redes sociales y económicas en torno a una familia de músicos entre el Renacimiento y el Barroco. Sevilla, Diputación, 2019.

Bolaños, P., "Comedias y comediantes en el coliseo de Écija (1772-1774)", en Teatro español del siglo XVIII: Tomo I y II, Lleida, Universidad, 1996, pp. 115-152.

Descripción analítica de las magnificas funciones que hizo... Xerez de la Frontera... con... motivo de la... proclamación... Carlos IV, Jerez, 1790.

Díez Martínez, M. , La música en Cádiz: la catedral y su proyección urbana, Cádiz, Universidad de Cádiz, 2004.

En celebridad del glorioso nombre de la Serma. Sra. Luisa de Borbón (Q.D.G.), princesa de Asturias, \&c., en el Nuevo Coliseo Real de San Lorenzo..., Cádiz, 1780.

Fenlon, I. "La Magnificencia como imagen civil: música y espacio ceremonial en Venecia a principios de la Edad Moderna", en Música y cultura urbana, Valencia, PUV, 2005, pp. 193-218.

Fernández de Andrada, P., De la naturaleza del Caballo, Sevilla, 1580.

García-Figueras, T. "La embajada de 'el gazzal' (1766)”, África. Revista de estudios hispanoafricanos. Segunda época, mayo, 1936.

Gembero-Ustárroz, M., "El contexto musical andaluz durante la estancia de la corte de Felipe V en Sevilla (1729-33)", en Sevilla y Corte. Las artes y el Lustro real (17291733), Madrid, Casa de Velázquez, 2010, pp. 301-311.

Gómez Fernández, L., Música, nobleza y mecenazgo. Los duques de Medina Sidonia en Sevilla y Sanlúcar de Barrameda (1445-1615), Cádiz, Universidad de Cádiz, 2017.

Kenyon de Pascual, B., "Clarines and trompetas: some further observations", Historic Brass Society Journal, 7, (1995), pp. 100-105.

Lorenzetti, S., Musica e identità nobiliare nell'italia del rinascimento Educazione, Mentalità, Immaginario, Florencia, Leo S. Olschki, 2003.

Manifiesto descriptivo de las demostraciones... Xerez de la Frontera celebraron... del nacimiento de los dos infantes gemelos... y paz con Inglaterra, Puerto de Santa María, 1784.

Mercado y Mendoza, G., Relevantes demostraciones con que la nobilíssima ciudad de 
Xerez de la Frontera manifestó en obsequios su lealtad y amor en festivos aplausos al cumplimiento de los catorze y felices años de el rey nuestro señor D. Carlos Segundo. Jerez de la Frontera, 1676.

Moreno Arana, J. A., "Música y poder municipal en Jerez de la Frontera. Siglos XVI-XVII", Historia, Instituciones y Documentos, 45, (2018), pp. 241-268.

Moreno Arana, J. A., Un episodio cultural de Jerez de la Frontera en el siglo XVI. Los libros del bachiller Diego de Aguilocho, Madrid, Bubok, 2019.

Noticia de las funciones executadas en... Xerez de la Frontera con motivo de la proclamación de Carlos IV, Madrid, 1790.

Ollero Lobato, F., "Las mascaradas, fiesta barroca en Sevilla", Potestas, 6, (2013), pp. 143173.

Puntual descripción... Xerez de la Frontera solemnizó la proclamación del rey... Carlos III, Sevilla, 1759.

Romero Bejarano, M., Los orígenes de la Semana Santa de Jerez, Jerez, 2019.

Romero Ferrer, A. y Moreno Mengíbar, A., Manuel García: de la tonadilla escénica a la ópera española (1775-1832), Cádiz, Universidad de Cádiz, 2006.

Ruiz Jiménez, J., "Ministriles y extravagantes en la celebración religiosa", en Políticas y prácticas musicales en el mundo de Felipe II: estudios sobre la música en España, sus instituciones y sus territorios en la segunda mitad del siglo XVI, Madrid, ICCMU, 2004, pp. 207-208.

Sancho de Sopranis, H. y Lastra Terry, J. de la, Historia de Jerez de la Frontera, Tomo II, Jerez, 1965.

Santos Conde, H., "Definiciones y usos del término 'concierto' en la documentación catedralicia española", Resonancias, 23, (2019), pp. 13-35.

Spínola y Torres, J., Descripción de la fiesta de cañas y toros celebradas en Jerez de la Frontera en 1630 con motivo del Nacimiento de príncipe D. Baltasar Carlos, Madrid, 1916.

Torre Molina, M. J. de la, Música y ceremonial en las fiestas reales de proclamación de España e Hispanoamérica (1746-1814), tesis doctoral de la Universidad de Granada, 2003.

Vílchez Ávila y Ochoa, T. de, Breue relacion en que se da cuenta de las fiestas... con que la... ciudad de Xerez de la Frontera ha celebrado el... natal de el... Príncipe de Asturias, Cádiz, 1707. 